\title{
D-Galactosamine/Lipopolysaccharide-Induced Hepatotoxicity Downregulates Sirtuin 1 in Rat Liver: Role of Sirtuin 1 Modulation in Hepatoprotection
}

\author{
M. K. KEMELO ${ }^{1}$, L. WOJNAROVÁ ${ }^{1}$, N. KUTINOVÁ CANOVÁ ${ }^{1}$, H. FARGHALI ${ }^{1}$ \\ ${ }^{1}$ Institute of Pharmacology, First Faculty of Medicine, Charles University, Prague, Czech Republic
}

Received February 27, 2014

Accepted April 23, 2014

On-line June 5, 2014

\begin{abstract}
Summary
D-Galactosamine/Lipopolysaccharide (D-GalN/LPS) is a well known model of hepatotoxicity that closely resembles acute liver failure (ALF) seen clinically. The role of sirtuin 1 in this model has not yet been documented. However, there have been a number of studies about the cytoprotective effects of resveratrol, a SIRT1 activator, in the liver. This study was aimed at elucidating the roles of SIRT1 protein expression or catalytic activity in DGalN/LPS model of hepatotoxicity. ALF was induced in male Wistar rats by intraperitoneal injection of D-GaIN and LPS. Some groups of animals were pretreated with resveratrol and/or EX527 (SIRT1 inhibitor). The effects of these treatments were evaluated by biochemical and Western blot studies. D-GaIN/LPS treatment was able to induce hepatotoxicity and significantly increase all markers of liver damage and lipid peroxidation. A dramatic decrease of SIRT1 levels in response to D-GaIN/LPS treatment was also documented. Resveratrol pretreatment attenuated D-GaIN/LPS-induced hepatotoxicity. EX-527 blocked the cytoprotective effects of resveratrol. However, both resveratrol and EX-527 pretreatments did not exhibit any significant effect on SIRT1 protein expression. Collectively, these results suggest that downregulation of SIRT1 expression is involved in the cytotoxic effects of D-GaIN/LPS model and SIRT1 activity contributes to the cytoprotective effects of resveratrol in the liver.
\end{abstract}

\section{Key words}

SIRT1 • Resveratrol • EX-527 • D-galactosamine/ Lipopolysaccharide $\bullet$ Hepatotoxicity

\author{
Corresponding author \\ M. K. Kemelo, Institute of Pharmacology, First Faculty \\ of Medicine, Charles University in Prague, Albertov 4, 12800 \\ Prague 2, Czech Republic. E-mail: mighty.kemelo@If1.cuni.cz
}

\section{Introduction}

Liver is a metabolically active organ responsible for biotransformation and clearance of xenobiotics from the body. It is an important target of drugs and pathogens that may initiate liver cell damage and compromise its overall function (Hong et al. 2009). Currently, there is no way to compensate for the absence of liver function in the long term and massive hepatic destruction often necessitates the need for liver transplantation (Chan et al. 2009). There is therefore an intensive search of safe, affordable and readily available agents that can protect the liver from fulminant damage (Cengiz et al. 2013).

The general strategy for prevention of liver damage includes reduction of reactive metabolites by using antioxidants (Bansal et al. 2005). Natural polyphenolic compounds such as resveratrol, quercetin, curcumin and silymarin possess antioxidant properties and anti-inflammatory effects and have been the subject of considerable research as liver protectants (Rivera et al. 2008, Haddad et al. 2011, Cerny et al. 2011, Lekic et al. 2013). Interest in resveratrol has skyrocketed over recent years due to its cytoprotective effects in many organs. For instance, it has been proven to be effective in attenuating vascular endothelial inflammation (Chen et al. 2013), diabetic nephropathy (Wen et al. 2013) and cholestatic liver injury (Ara et al. 2005). Moreover, our experimental 
studies, both in vivo and in vitro, demonstrated that resveratrol is effective in protecting hepatocytes against D-GalN/LPS-induced hepatotoxicity (Farghali et al. 2009). However, the exact mechanism by which resveratrol exerts its cytoprotective effects is still elusive.

One of the hypotheses is that resveratrol allosterically activates an $\mathrm{NAD}^{+}$-dependent histone deacetylase SIRT1 which has multifaceted functions and plays a critical role in cellular stress responses (Howitz et al. 2003). On activation, SIRT1 can deacetylate and turn on anti-inflammatory and antioxidant factors such as FOXO (Brunet et al. 2004, Hasegawa et al. 2008, Tanno et al. 2010). The many positive health benefits of SIRT1 can also be explained in part by inhibition of proinflammatory factors such as NF-אB (Yeung et al. 2004, Farghali et al. 2013). This notion is also supported by the finding that SIRT1 deficiency in experimental animals exacerbates conditions such as nephrosclerosis and hyperglycemia which are normally ameliorated by resveratrol treatment (Wang et al. 2011, Vasko et al. 2014). Nonetheless, the validity of direct SIRT1 activation by resveratrol has been challenged by many researchers. Some studies suggest that activation of SIRT1 by resveratrol is an experimental artifact and resveratrol's health benefits and sirtuins are not related (Beher et al. 2009). Besides SIRT1, there are other potential target molecules such as AMPK that may be involved in the aforementioned cytoprotective effects of resveratrol (Biasutto et al. 2012).

This ambiguity prevents development of more potent resveratrol-like compounds which are promising liver protectants. The goal of the present study was to elucidate the roles of SIRT1 protein expression and catalytic activity in D-GalN/LPS model of hepatotoxicity.

\section{Materials and Methods}

\section{Chemicals}

Lipopolysaccharide from Escherichia coli K-235

(LPS), D-galactosamine hydrochloride (D-GalN), resveratrol (3,4',5-trihydroxy-trans-stilbene, 5-[(1E)-2-(4hydroxyphenyl)ethenyl]-1,3-benzenediol, $\geq 99 \%$ GC), EX-527 (6-chloro-2,3,4,9-tetrahydro-1H-Carbazole-1carboxamide, $\geq 98 \%$ HPLC), Tris-HCl, Nonidet P40 Substitute, dimethyl sulfoxide (DMSO), isopropyl alcohol, Tween 20, 2-thiobarbituric acid, tetraethoxypropane, trichloroacetic acid (TCA), sodium dodecyl sulphate, ammonium persulfate, methanol, glycine, $\quad \mathrm{N}, \mathrm{N}, \mathrm{N}^{\prime}, \mathrm{N}^{\prime \prime}$-tetramethylethylenediamine, 2-mercaptoethanol, bromophenol blue, glycerol, $\mathrm{N}, \mathrm{N}^{\prime}$-methylenebis (acrylamide), $\mathrm{NaCl}, \mathrm{KCl}, \mathrm{Na}_{2} \mathrm{HPO}_{4}$, $\mathrm{KH}_{2} \mathrm{PO}_{4}$, ammonium molybdate tetrahydrate, hydrogen peroxide, filter paper, nitrocellulose membrane, antimouse IgG (whole molecule)-peroxidase antibody and mouse monoclonal anti-B-actin antibody were purchased from Sigma-Aldrich (Prague, Czech Republic). SirT1 (1F3) mouse mAb antibody was from Cell Signaling Technology through Biotech A.S. (Prague, Czech Republic). Non-fat dry milk was from Biotech A.S. (Prague, Czech Republic). Water for injection $100 \% \mathrm{w} / \mathrm{v}$ was from Baxter (Czech Republic, Prague). Bio-Rad protein assay dye reagent was from Bio-Rad (Prague, Czech Republic).

\section{Animals}

Male Wistar rats, 250-400 g body weight, were purchased from Velaz-Lysolaje, Czech Republic. They were given water and a standard granulated diet ad libitum. They were maintained under standard conditions (12-h light-dark cycle, $22 \pm 2{ }^{\circ} \mathrm{C}$ temperature and 50 $\pm 10 \%$ relative humidity). The animals received humane care in accordance with the ethical guidelines of the First Faculty of Medicine, Charles University in Prague.

\section{Experimental design}

The animals were allowed to acclimatize to the vivarium for seven days before being used in the experiments.

Then they were randomly divided into five groups of six animals each and treated as follows:

- Group 1 - Control: DMSO (500 $\mu \mathrm{l} / \mathrm{kg})$ + saline (1 ml/kg)

- Group 2 - resveratrol (2.3 mg/kg)

- Group 3 - D-GalN (400 mg/kg) + LPS (10 $\mu \mathrm{g} / \mathrm{kg})$

- Group 4 - resveratrol (2.3 mg/kg) + D-GalN (400 mg/kg) + LPS (10 $\mu \mathrm{g} / \mathrm{kg})$

- Group 5 - EX-527 (1 mg/kg) + resveratrol $(2.3 \mathrm{mg} / \mathrm{kg})+\mathrm{D}-\mathrm{GalN}(400 \mathrm{mg} / \mathrm{kg})+\mathrm{LPS}(10 \mu \mathrm{g} / \mathrm{kg})$

The above doses were selected based on our previous experimental studies (Farghali et al. 2009, Cerny et al. 2011, Lekic et al. 2013). All treatments were administered intraperitoneally. Group 1 received only DMSO and physiologic solution. Group 2 was given resveratrol dissolved in DMSO. Group 3 got D-GalN and LPS dissolved in physiologic solution. Group 4 was pretreated with resveratrol $60 \mathrm{~min}$ before induction of hepatic failure. Group 5 was pretreated with EX-527 $30 \mathrm{~min}$ before resveratrol treatment that was followed 
60 min later by D-GalN/LPS treatment. At the end of treatment period $(6 \mathrm{~h})$, the animals were anesthetized with diethylether and then euthanized by exsanguination. Their blood samples were immediately collected into heparinized tubes for biochemical investigations. Their liver samples were excised and either homogenized for further biochemical analysis or snap-frozen in liquid nitrogen for Western blot studies.

\section{Biochemical investigations}

The extent of liver damage was assessed by detecting the levels of transaminases (ALT, AST) and bilirubin in plasma using commercially available diagnostic kits from Synlab (Prague, Czech Republic). Conjugated dienes (CD) and thiobarbituric acid reacting substances (TBARS) were measured in liver homogenate as previously described by Farghali et al. (2009).

\section{Immunoblotting}

Liver samples were homogenized and lysed in NP40 lysis buffer supplemented with protease and phosphatase inhibitors. Equivalent amounts of lysate protein, $20 \mu \mathrm{g}$ of protein measured by the Bradford method, were then subjected to $10 \%$ SDS-PAGE and electrophoretically transferred onto a nitrocellulose membrane. After blocking the nitrocellulose membranes by incubation with Tris-buffered saline containing $5 \%$ non-fat milk (for $1 \mathrm{~h}$ at room temperature), the membranes were incubated with primary antibodies overnight at $4^{\circ} \mathrm{C}$. The primary antibodies used were SIRT1 (1:1000 dilution, Cell Signaling Technology) and beta actin (1:5000, Sigma Aldrich). The following day, the membranes were washed in TBST and incubated with anti-mouse IgG (whole molecule)-peroxidase antibody (1:80000, Sigma Aldrich) at room temperature for $1 \mathrm{~h}$. Proteins were visualized by enhanced chemiluminescence (GeneTiCA s.r.o., Prague, Czech Republic). Densitometric analysis was performed using the Quantity One software (Bio-Rad, Prague, Czech Republic).

\section{Statistical analyses}

All data are expressed as mean \pm SEM of six animals used in each group. Statistical evaluation of the data was performed using one way ANOVA followed by Tukey-Kramer comparison test. $\mathrm{P}<0.05$ was considered to have statistical significance.
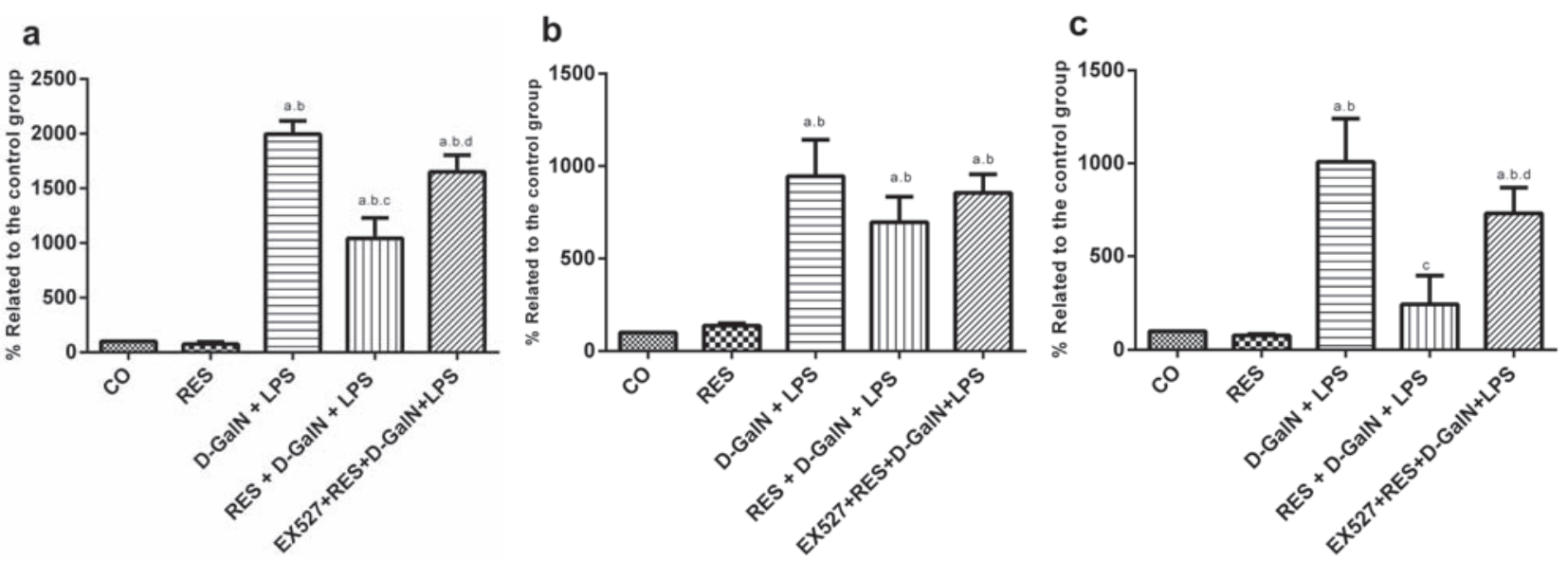

Fig. 1. Effects of resveratrol and EX-527 pretreatment in lipopolysaccharide-induced hepatitis in D-galactosamine sensitized rats (DGalN/LPS) on plasma levels of alanine aminotransferase ALT (a), aspartate aminotransferase AST (b) and bilirubin (c). CO, control group; RES, $2.3 \mathrm{mg} / \mathrm{kg}$ resveratrol; D-GalN + LPS, $400 \mathrm{mg} / \mathrm{kg}$ D-galactosamine with $10 \mu \mathrm{g} / \mathrm{kg}$ lipopolysaccharide; RES + D-GalN + LPS, $2.3 \mathrm{mg} / \mathrm{kg}$ resveratrol + D-GalN + LPS; EX-527 + RES + D-GalN + LPS, $1 \mathrm{mg} / \mathrm{kg}$ EX-527 plus combination of previous substances. Data are expressed as means \pm SEM $(n=6)$. ${ }^{a} P<0.05$ versus $C O,{ }^{b} P<0.05$ versus the $R E S,{ }^{c} P<0.05$ versus $D$-GalN + LPS, ${ }^{d} P<0.05$ versus RES + D-GalN + LPS

\section{Results}

Effect of resveratrol and EX-527 pretreatment in $D$-GalN/LPS-induced liver injury

We first sought to define the role of resveratrol and EX-527 pretreatment in D-GalN/LPS-induced liver injury. For this, we measured the levels of ALT, AST and bilirubin in plasma (Fig. 1). Treatment of animals with D-GalN/LPS was able to induce hepatotoxicity as evidenced by a significant increase in transaminases and bilirubin levels relative to the negative control groups (CO and RES). There was over 20-fold increase in ALT 
levels and slightly less with AST and bilirubin. Resveratrol alone had no significant effects on these markers. However, resveratrol pretreatment in D-GalN/LPS rats significantly lowered the ALT and bilirubin levels. There was also the same trend with AST, despite the statistical non-significance. These findings demonstrate that resveratrol was effective in attenuating D-GalN/LPS induced hepatotoxicity. EX-527, on the other hand, blocked the effects of resveratrol and significantly increased the ALT and bilirubin levels. EX-527 is one of the few available SIRT1 inhibitors which combine high potency with specificity. Hence this finding provides a clear indication that the catalytic activity of SIRT1 is required for the cytoprotective effects of resveratrol.
Effect of resveratrol and EX-527 pretreatment on lipid peroxidation in D-GalN/LPS treated rats

To firmly establish the role of resveratrol and EX-527 pretreatment in D-GalN/LPS-induced liver injury, we measured the levels of lipid peroxidation using TBARS and CD in homogenate (Fig. 2). Both CD and TBARS were significantly enhanced after D-GalN/LPS treatment reflecting increased peroxidation. Resveratrol pretreatment reduced the levels of both markers by more than a fold. The anti-peroxidative effects of resveratrol were blocked by EX-527 as evidenced by a significant increase in both the TBARS and CD levels. The extent of lipid peroxidation corresponds to the liver function tests above (Fig. 1) because lipid peroxidation is an index of oxidative stress (Niki 2008). a

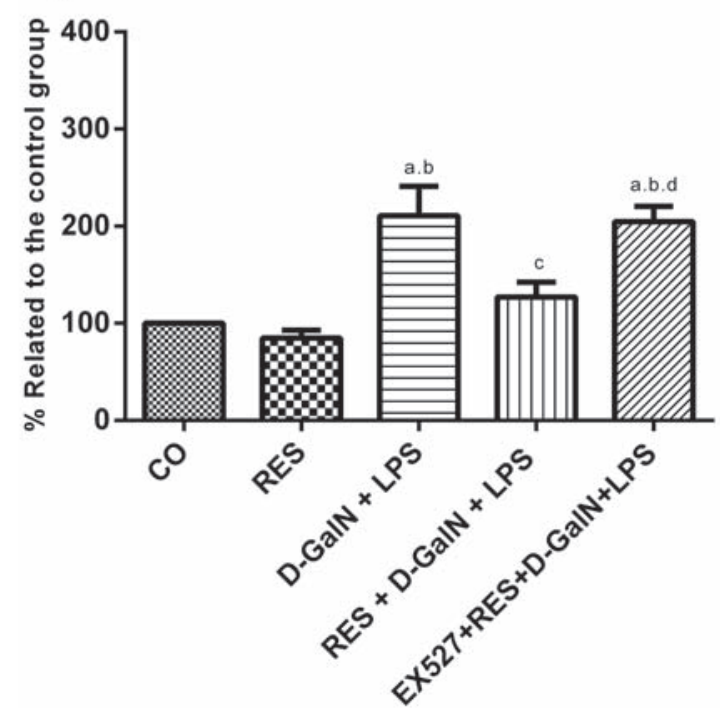

b

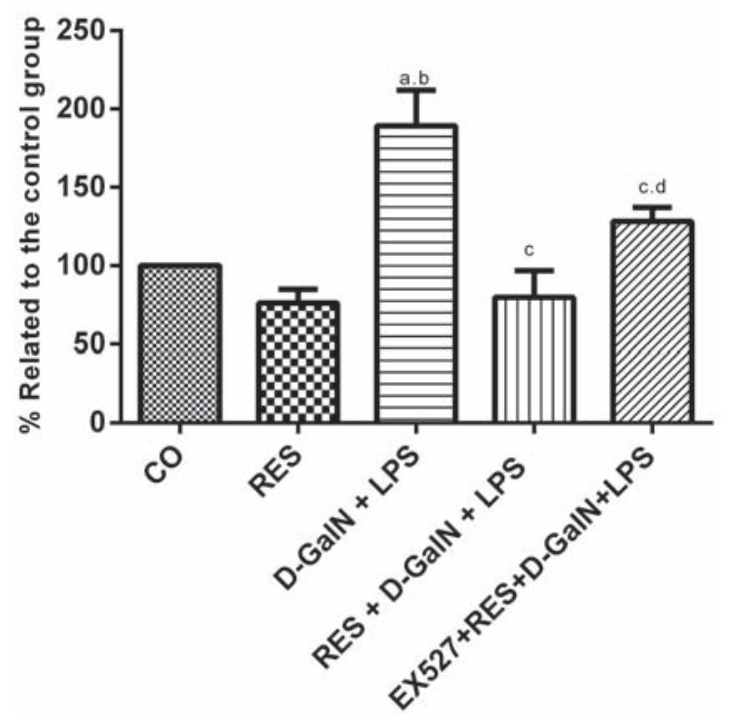

Fig. 2. Effects of resveratrol pretreatment in lipopolysaccharide-induced hepatitis in D-galactosamine sensitized rats (LPS/D-GalN) on the formation of (a) Conjugated dienes (CD) and (b) Thiobarbituric acid reactive substances (TBARS) in liver homogenate. CO, control group; RES, $2.3 \mathrm{mg} / \mathrm{kg}$ resveratrol; D-GalN + LPS, $400 \mathrm{mg} / \mathrm{kg}$ D-galactosamine with $10 \mu \mathrm{g} / \mathrm{kg}$ lipopolysaccharide; RES + D-GalN + LPS, $2.3 \mathrm{mg} / \mathrm{kg}$ resveratrol + D-GalN + LPS; EX-527 + RES + D-GalN + LPS, $1 \mathrm{mg} / \mathrm{kg}$ EX-527 plus combination of previous substances. Data are expressed as mean \pm SEM $(n=6) .{ }^{\text {a }} P<0.05$ versus $C O,{ }^{b} P<0.05$ versus the $R E S,{ }^{c} P<0.05$ versus $D-G a I N+L P S,{ }^{d} P<0.05$ versus RES + D-GalN + LPS

Effect of resveratrol and EX-527 pretreatment on SIRT1 expression levels in D-GalN/LPS treated rats

A Western blot analysis was performed to confirm if SIRT1 is detected in the liver and how its expression is affected by resveratrol or EX-527 pretreatment. As shown in Figure 3, we found that SIRT1 was ubiquitously expressed in liver samples from all the animal groups. Resveratrol alone, did not have any statistically significant effect on the total endogenous amount of SIRT1. However, treatment with D-GalN/LPS dramatically decreased SIRT1 expression levels. In spite of an increasing trend on the blot, resveratrol pretreatment of D-GalN/LPS rats did not have any statistical significance on SIRT1 expression. Likewise, there was no significant change in SIRT1 expression levels in response to EX-527 pretreatment. This suggests that there may be other ways of modulating the aforementioned biochemical effects of resveratrol (Fig. 1 and Fig. 2) in the liver rather than alterations in SIRT1 expression. 
a

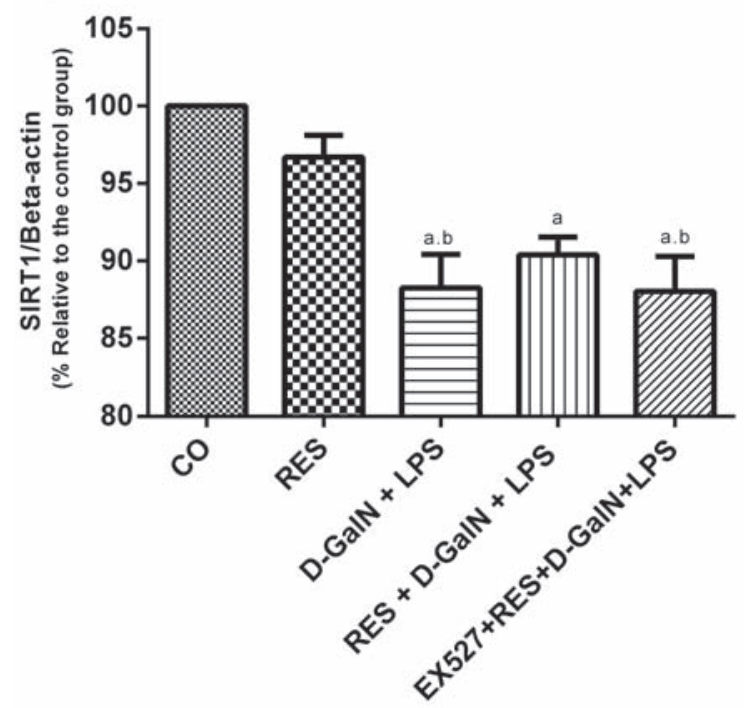

b

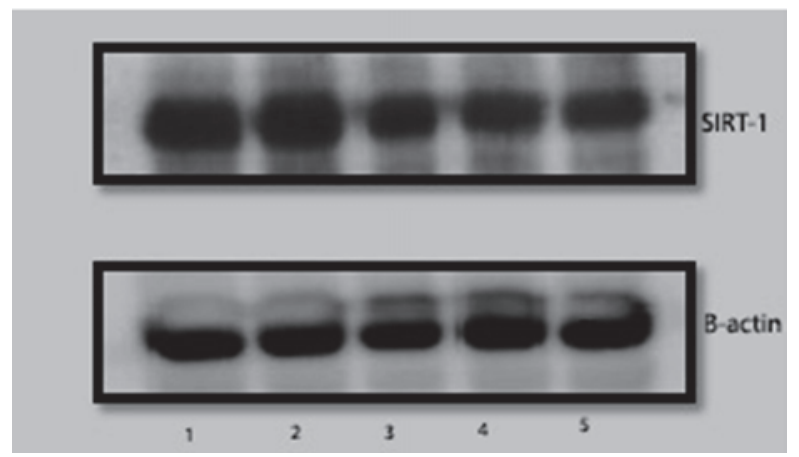

Fig. 3. Effects of resveratrol and EX-527 pretreatment on SIRT1 expression. (a) Quantification of SIRT1 expression levels by densitometry. Band intensity measurements were done using Bradford software. In each panel, the intensity of a given band was normalized to the intensity of the corresponding $\beta$-actin band. CO, control group; RES, $2.3 \mathrm{mg} / \mathrm{kg}$ resveratrol; D-GalN + LPS, $400 \mathrm{mg} / \mathrm{kg}$ D-galactosamine with $10 \mu \mathrm{g} / \mathrm{kg}$ lipopolysaccharide; RES + D-GalN + LPS, $2.3 \mathrm{mg} / \mathrm{kg}$ resveratrol + D-GalN + LPS; EX-527 + RES + D-GalN + LPS, $1 \mathrm{mg} / \mathrm{kg}$ EX-527 plus combination of previous substances. Data are expressed as mean $\pm S E M(n=6)$. ${ }^{\text {a }} P<0.05$ versus CO, ${ }^{b} P<0.05$ versus the RES. (b) Representative Western blot images lanes: 1) CO, 2) RES, 3) D-GaIN + LPS, 4) RES + D-GaIN + LPS, 5) $E X-527$ + RES + D-GalN + LPS

\section{Discussion}

Acute liver failure is one of the most challenging conditions in internal medicine. It occurs when the previously healthy liver cells are seriously injured and die giving rise to complications such as jaundice, coagulopathy and encephalopathy within few days (McDowell et al. 2010). Most common causes of ALF are viral hepatitis and drug toxins (Gotthardt et al. 2007). Its prognosis is dismissal and in most cases orthotopic liver transplantation is the only definitive curative treatment (Russo and Parola 2011). However, the scarcity of donors often precludes transplantation (Smith and Murphy 2008). There is therefore an intensive search of therapeutic strategies to prevent the onset of ALF by preventing apoptotic cell death of hepatocytes in experimental models (Hirono et al. 2001).

D-GalN/LPS-induced acute liver injury in experimental animals is a well-known in vivo model that closely resemble ALF seen clinically (Kosai et al. 1999). In this model, LPS, an endotoxin, activates macrophages and Kupffer cells to produce TNF- $\alpha$. Through complex signaling cascades, TNF- $\alpha$ activates caspases and transcription factors such as NF- $\kappa \mathrm{B}$ leading to cell demise (Silverstein 2004, Bradham et al. 2008). D-GalN on the other hand selectively depletes uridine nucleotides in the liver, inhibits RNA synthesis in hepatocytes and potentiates the acute toxicity of LPS (Alcorn et al. 1992, Lekic et al. 2011). The combined effects of these two agents produce a more severe form of liver injury consistent with ALF (Leist et al. 1995). In this study, $10 \mu \mathrm{g} / \mathrm{kg}$ of LPS and $400 \mathrm{mg} / \mathrm{kg}$ of D-GalN markedly increased the plasma levels of transaminases confirming that fatal liver injury occurred within six hours of treatment. ALT is the most reliable, sensitive and specific marker of liver injury (Dufour et al. 2000). It is abundant in hepatocytes and is released into serum as a result of hepatocellular damage, so its level in plasma approximates the extent of liver damage (Hsueh et al. 2011). Likewise, D-GalN/LPS treatment augmented lipid peroxidation as shown by increase in the TBARS and conjugated dienes. Lipid peroxidation alters the physical and chemical properties of cell membranes and their fluidity resulting in cytolysis and cell death (Pradeep et al. 2009). The levels of bilirubin were also increased in response to D-GalN/LPS treatment. Bilirubin plays an important role as an antioxidant by scavenging peroxyl radicals and preventing oxidation of fatty acids and proteins (Mayer 2000). Its activity is augmented in oxidative stress as an adaptive mechanism. Of interest, our Western blots revealed a significant and dramatic decrease in SIRT1 expression levels after D-GalN/LPS treatment (Fig. 3). The precise mechanism by which D-GalN/LPS treatment represses SIRT1 expression was 
not investigated in this study. However, several studies suggest that generation of ROS plays a key role in the cytotoxic effects of this model (Uchikura et al. 2004). For instance, LPS may execute induction of iNOS and subsequent peroxynitrite anion which can oxidize a wide array of molecules within cells including lipids and DNA (Szabó and Ohshima 1997, Morikawa et al. 2004, Pacher et al. 2007, Lekic et al. 2013). Moreover, some recent studies have shown that microRNAs such as miR-34a can downregulate SIRT1 expression in response to oxidative stress and therefore augment liver damage (Yamakuchi 2012, Choi and Kemper 2013). In brief, our studies add to the mounting evidence that SIRT1 expression is decreased to some extent by the degree of oxidative stress.

Pretreatment with resveratrol ameliorated D-GalN/LPS-induced liver damage as evidenced by a decrease in transaminases and other markers of oxidative stress. Interestingly, resveratrol pretreatment did not have any significant effect on SIRT1 expression level when compared to D-GalN/LPS treatment. This demonstrates that there are other ways in which resveratrol exerts its cytoprotective effects in the liver, beside upregulation of SIRT1 expression reported in some studies (Wang et al. 2013). SIRT1 expression and activity can be modulated at different levels. One school of thought is that resveratrol allosterically activates SIRT1. It binds to the noncatalytic N-terminus of SIRT1 to cause a conformational change that lowers its Michaelis constant (Howitz et al. 2003). SIRT1 in turn deacetylates and suppresses transcription factors such as $\mathrm{NF}-\kappa \mathrm{B}$ responsible for induction of pro-inflammatory cytokines and proapoptotic factors (Yeung et al. 2004). SIRT1 also upregulates FOXO-dependent antioxidants such as catalase and MnSOD which protect against oxidative stress-induced cellular apoptosis (Hasegawa et al. 2008, Tanno et al. 2010). However, the hypothesis that resveratrol is a bona fide SIRT1 agonist has been challenged by many authors (Beher et al. 2009, Baur et al. 2012). SIRT1 is not the only resveratrol-sensitive molecule that may have protective downstream effects. Another potential resveratrol target is the main metabolic regulator, AMPK (Centeno-Baez et al. 2011). SIRT1 and AMPK mutually coexist, share many common targets and have many overlapping cytoprotective effects (Ruderman et al. 2010, Farghali et al. 2013). It is also possible that SIRT1 and AMPK are interdependent and resveratrol activates SIRT1 through AMPK (Park et al. 2012). While the exact mechanism of resveratrol is yet unknown, within the experimental conditions of the present study, it seems that SIRT1 expression does not contribute to the cytoprotective effects of resveratrol in the liver.

To further demonstrate the role of SIRT1 catalysis in the cytoprotective effects of resveratrol, we pretreated another group of animals with a SIRT1 inhibitor, EX-527. EX-527 was chosen because it is more potent than other available SIRT1 inhibitors such as nicotinamide, splitomicin and sirtinol (Solomon et al. 2006). Furthermore, EX-527 is more selective for SIRT1 than other closely related histone deacetylases (Napper et al. 2005). However, its inhibition mechanisms are not fully understood. SIRT1 couples lysine deacetylation to NAD hydrolysis to yield nicotinamide and O-acetylADP-ribose (Jackson and Denu 2002, Blander and Guarente 2004). Kinetic analyses suggest that EX-527 binds to the SIRT1 C-pocket after release of nicotinamide and prevent the release of O-acetyl-ADP-ribose (Napper et al. 2005, Gertz et al. 2013). Despite non-significant/ negligible effects on SIRT1 expression levels, EX-527 significantly blocked the protective effects of resveratrol and augmented liver damage (Fig. 1 and Fig. 2). Taken together, these findings confirm that the catalytic activity of SIRT1 plays a key role in the cytoprotective effects of resveratrol in the liver. If the enzymatic activity of SIRT1 is inhibited, then the protective effects of resveratrol are also concomitantly blocked.

In conclusion, we affirm our previous findings that resveratrol is protective against D-GalN/LPS induced hepatotoxicity in rodents. Resveratrol has antioxidant properties and protects cells against lipid peroxidation. Inhibition of SIRT1 by EX-527 renders resveratrol ineffective and exacerbates D-GalN/LPS-induced liver injury. According to our study, SIRT1 downregulation is an involved step in the hepatotoxic effects of D-GalN/LPS treatment but the roles of resveratrol and EX-527 on SIRT1 expression were not documented in this study.

\section{Conflict of Interest}

There is no conflict of interest.

\section{Acknowledgements}

This study was supported by the research program PRVOUK-P25/LF1/2 and grants GAUK-916314 and IGA MZ NT/14017-3/2013. The authors would like to thank Libuse Slehobrova for her skillful technical assistance. 


\section{Abbreviations}

AMPK, adenosine monophosphate-activated protein kinase; D-GalN, D-galactosamine; FLF, fulminant liver failure; FOXO, forkhead box-O; LPS, lipopolysaccharide; MnSOD, manganese superoxide dismutase; NAD, nicotinamide adenine dinucleotide; $\mathrm{NF}-\mathrm{kB}$, nuclear factor-kappaB; ROS, reactive oxygen species; SIRT1, sirtuin 1, silent information regulator T1; TNF- $\alpha$, tumor necrosis factor alpha

\section{References}

ALCORN JM, FIERER J, CHOJKIER M: The acute phase response protects mice from D-galactosamine sensitization to endotoxin and tumor necrosis factor-alpha. Hepatology 15: 122-129, 1992.

ARA C, KIRIMLIOGLU H, KARABULUT AB, COBAN S, AY S, HARPUTLUOGLU M, KIRIMLIOGLU V, YILMAZ S: Protective effect of resveratrol against oxidative stress in cholestasis. J Surg Res 127: 112-117, 2005.

BANSAL AK, BANSAL M, SONI G, BHATNAGAR D: Protective role of Vitamin E pre-treatment on Nnitrosodiethylamine induced oxidative stress in rat liver. Chem Biol Interact 156: 101-111, 2005.

BAUR JA, MAI A, GUARENTE L: Revelations into resveratrol's mechanism. Nat Med 18: 500-501, 2012.

BEHER D, WU J, CUMINE S, KIM KW, LU SC, ATANGAN L, WANG M: Resveratrol is not a direct activator of SIRT1 enzyme activity. Chem Biol Drug Des 74: 619-624, 2009.

BIASUTTO L, MATTAREI A, ZORATTI M: Resveratrol and health: the starting point. Chembiochem 13: 1256-1259, 2012.

BLANDER G, GUARENTE L: The Sir2 family of protein deacetylases. Annu Rev Biochem 73: 417-435, 2004.

BRADHAM CA, PLÜMPE J, MANNS MP, BRENNER DA, TRAUTWEIN C: Mechanisms of hepatic toxicity. I. TNF-induced liver injury. Am J Physiol 275: G387-G392, 2008.

BRUNET A, SWEENEY LB, STURGILL JF, CHUA KF, GREER PL, LIN Y, TRAN H, ROSS SE, MOSTOSLAVSKY R, COHEN HY, HU LS, CHENG HL, JEDRYCHOWSKI MP, GYGI SP, SINCLAIR DA, ALT FW, GREENBERG ME: Stress-dependent regulation of FOXO transcription factors by the SIRT1 deacetylase. Science 303: 2011-2015, 2004.

CENGIZ N, KAVAK S, GÜZEL A, OZBEK H, BEKTAŞ H, HIM A, ERDOĞAN E, BALAHOROĞLU R: Investigation of the hepatoprotective effects of Sesame (Sesamumindicum L.) in carbon tetrachloride-induced liver toxicity. J Membr Biol 246: 1-6, 2013.

CENTENO-BAEZ C, DALLAIRE P, MARETTE A: Resveratrol inhibition of inducible nitric oxide synthase in skeletal muscle involves AMPK but not SIRT1. Am J Physiol 301: E922-E930, 2011.

CERNÝ D, LEKIĆ N, VÁŇOVÁ K, MUCHOVÁ L, HOŘÍNEK A, KMONÍČKOVÁ E, ZÍDEK Z, KAMENÍKOVÁ L, FARGHALI H: Hepatoprotective effect of curcumin in lipopolysaccharide/-galactosamine model of liver injury in rats: relationship to HO-1/CO antioxidant system. Fitoterapia 82: 786-791, 2011.

CHAN AC, FAN ST, LO CM, LIU CL, CHAN SC, NG KK, YONG BH, CHIU A, LAM BK: Liver transplantation for acute-on-chronic liver failure. Hepatol Int 3: 571-581, 2009.

CHEN ML, YI L, JIN X, LIANG XY, ZHOU Y, ZHANG T, XIE Q, ZHOU X, CHANG H, FU YJ, ZHU JD, ZHANG QY, MI MT: Resveratrol attenuates vascular endothelial inflammation by inducing autophagy through the cAMP signaling pathway. Autophagy 9: 2033-45. 2013.

CHOI SE, KEMPER JK: Regulation of SIRT1 by MicroRNAs. Mol Cells 36: 385-392, 2013.

DUFOUR DR, LOTT JA, NOLTE FS, GRETCH DR, KOFF RS, SEEFF LB: Diagnosis and monitoring of hepatic injury. I. Performance characteristics of laboratory tests. Clin Chem 46: 2027-2049, 2000.

FARGHALI H, CERNÝ D, KAMENÍKOVÁ L, MARTÍNEK J, HORÍNEK A, KMONÍCKOVÁ E, ZÍDEK Z: Resveratrol attenuates lipopolysaccharide-induced hepatitis in D-galactosamine sensitized rats: role of nitric oxide synthase 2 and heme oxygenase-1. Nitric Oxide 21: 216-225, 2009.

FARGHALI H, KUTINOVÁ CANOVÁ N, LEKIĆ N: Resveratrol and related compounds as antioxidants with an allosteric mechanism of action in epigenetic drug targets. Physiol Res 62: 1-13, 2013. 
GERTZ M, FISCHER F, NGUYEN GT, LAKSHMINARASIMHAN M, SCHUTKOWSKI M, WEYAND M, STEEGBORN C: Ex-527 inhibits Sirtuins by exploiting their unique NAD ${ }^{+}$-dependent deacetylation mechanism. Proc Natl Acad Sci USA 110: E2772-E2781, 2013.

GOTTHARDT D, RIEDIGER C, WEISS KH, ENCKE J, SCHEMMER P, SCHMIDT J, SAUER P: Fulminant hepatic failure: etiology and indications for liver transplantation. Nephrol Dial Transplant 22: 5-8, 2007.

HADDAD Y, VALLERAND D, BRAULT A, HADDAD PS: Antioxidant and hepatoprotective effects of silibinin in a rat model of nonalcoholic steatohepatitis. Evid Based Complement Alternat Med 2011: article ID 647903, 2011.

HASEGAWA K, WAKINO S, YOSHIOKA K, TATEMATSU S, HARA Y, MINAKUCHI H, WASHIDA N, TOKUYAMA H, HAYASHI K, ITOH H: Sirt1 protects against oxidative stress-induced renal tubular cell apoptosis by the bidirectional regulation of catalase expression. Biochem Biophys Res Commun 372: 51-56, 2008.

HIRONO S, NAKAMA T, TSUBOUCHI H: Molecular mechanisms of D-galactosamine/lipopolysaccharide-induced fulminant hepatic failure in mice and the effects of therapeutic agents. In: Trends in Gastroenterology and Hepatology: Millennium 2000. Niigata, 2001, pp 59-62.

HONG JY, LEBOFSKY M, FARHOOD A, JAESCHKE H: Oxidant stress-induced liver injury in vivo: role of apoptosis, oncotic necrosis, and c-Jun NH2-terminal kinase activation. Am J Physiol 296: G572-G581, 2009.

HOWITZ KT, BITTERMAN KJ, COHEN HY, LAMMING DW, LAVU S, WOOD JG, ZIPKIN RE, CHUNG P, KISIELEWSKI A, ZHANG LL, SCHERER B, SINCLAIR DA: Small molecule activators of Sirtuins extend Saccharomycetescerevisiae lifespan. Nature 425: 191-196, 2003.

HSUEH CJ, WANG JH, DAI L, LIU CC: Determination of alanine aminotransferase with an electrochemical nano Ir-C biosensor for the screening of liver diseases. Biosensors 1: 107-117, 2011.

JACKSON MD, DENU JM: Structural identification of 2'- and 3'-O-acetyl-ADP-ribose as novel metabolites derived from the Sir2 family of beta -NAD ${ }^{+}$-dependent histone/protein deacetylases. J Biol Chem 277: 18535-18544, 2002.

KOSAI K, MATSUMOTO K, FUNAKOSHI H, NAKAMURA T: Hepatocyte growth factor prevents endotoxininduced lethal hepatic failure in mice. Hepatology 30: 151-159, 1999.

LEIST M, GANTNER F, BOHLINGER I, TIEGS G, GERMANN PG, WENDEL A: Tumor necrosis factor-induced hepatocyte apoptosis precedes liver failure in experimental murine shock models. Am J Pathol 146: 12201234, 1995.

LEKIĆ N, CERNÝ D, HOŘÍNEK A, PROVAZNÍK Z, MARTÍNEK J, FARGHALI H: Differential oxidative stress responses to D-galactosamine-lipopolysaccharide hepatotoxicity based on real time PCR analysis of selected oxidant/antioxidant and apoptotic gene expressions in rat. Physiol Res 60: 549-558, 2011.

LEKIĆ N, CANOVÁ NK, HOŘÍNEK A, FARGHALI H: The involvement of hemeoxygenase 1 but not nitric oxide synthase 2 in a hepatoprotective action of quercetin in lipopolysaccharide-induced hepatotoxicity of Dgalactosamine sensitized rats. Fitoterapi 87: 20-26, 2013.

MAYER M: Association of serum bilirubin concentration with risk of coronary artery disease. Clin Chem 46: 17231727, 2000.

MCDOWELL TORRES D, STEVENS RD, GURAKAR A: Acute liver failure: a management challenge for the practicing gastroenterologist. Gastroenterol Hepatol (NY) 6: 444-450, 2010.

MORIKAWA A, KOIDE N, SUGIYAMA T, MU MM, HASSAN F, ISLAM S, ITO H, MORI I, YOSHIDA T, YOKOCHI T: The enhancing action of D-galactosamine on lipopolysaccharide-induced nitric oxide production in RAW 264.7 macrophage cells. FEMS Immunol Med Microbiol 41: 211-218, 2004.

NAPPER AD, HIXON J, MCDONAGH T, KEAVEY K, PONS JF, BARKER J, YAU WT, AMOUZEGH P, FLEGG A, HAMELIN E, THOMAS RJ, KATES M, JONES S, NAVIA MA, SAUNDERS JO, DISTEFANO PS, CURTIS R: Discovery of indoles as potent and selective inhibitors of the deacetylase SIRT1. J Med Chem $\mathbf{4 8}$ : 8045-8054, 2005.

NIKI E: Lipid peroxidation products as oxidative stress biomarkers. Biofactors 34: 171-180, 2008.

PACHER P, BECKMAN JS, LIAUDET L: Nitric oxide and peroxynitrite in health and disease. Physiol Rev 87: 315424, 2007. 
PARK SJ, AHMAD F, PHILP A, BAAR K, WILLIAMS T, LUO H, KE H, REHMANN H, TAUSSIG R, BROWN AL, KIM MK, BEAVEN MA, BURGIN AB, MANGANIELLO V, CHUNG JH: Resveratrol ameliorates aging-related metabolic phenotypes by inhibiting cAMP phosphodiesterases. Cell 148: 421-433, 2012.

PRADEEP HA, KHAN S, RAVIKUMAR K, AHMED MF, RAO MS, KIRANMAI M, REDDY DS, AHAMED SR, IBRAHIM M: Hepatoprotective evaluation of Anogeissus latifolia: in vitro and in vivo studies. World $J$ Gastroenterol 15: 4816-4822, 2009.

RIVERA H, SHIBAYAMA M, TSUTSUMI V, PEREZ-ALVAREZ V, MURIEL P: Resveratrol and trimethylated resveratrol protect from acute liver damage induced by $\mathrm{CCl}_{4}$ in the rat. $J$ Appl Toxicol 28: 147-155, 2008.

RUDERMAN NB, XU XJ, NELSON L, CACICEDO JM, SAHA AK: AMPK and SIRT1: a long-standing partnership? Am J Physiol 298: E751-E760, 2010.

RUSSO FP, PAROLA M: Stem and progenitor cells in liver regeneration and repair. Cytotherapy 13: 135-144, 2011.

SILVERSTEIN R: D-galactosamine lethality model: scope and limitations. J Endotoxin Res 10: 147-162, 2004.

SMITH M, MURPHY P: A historic opportunity to improve organ donation rates in the UK. Br J Anaesth 100: 735-737, 2008.

SOLOMON JM, PASUPULETI R, XU L, MCDONAGH T, CURTIS R, DISTEFANO PS, HUBER LJ: Inhibition of SIRT1 catalytic activity increases p53 acetylation but does not alter cell survival following DNA damage. Mol Cell Biol 26: 28-38, 2006.

SZABÓ C, OHSHIMA H: DNA damage induced by peroxynitrite: subsequent biological effects. Nitric Oxide 1: 373385, 1997.

TANNO M, KUNO A, YANO T, MIURA T, HISAHARA S, ISHIKAWA S, SHIMAMOTO K, HORIO Y: Induction of manganese superoxide dismutase by nuclear translocation and activation of SIRT1 promotes cell survival in chronic heart failure. J Biol Chem 285: 8375-8382, 2010.

UCHIKURA K, WADA T, HOSHINO S, NAGAKAWA Y, AIKO T, BULKLEY GB, KLEIN AS, SUN Z: Lipopolysaccharides induced increases in Fas ligand expression by Kupffer cells via mechanisms dependent on reactive oxygen species. Am J Physiol 287: G620-G626, 2004.

VASKO R, XAVIER S, CHEN J, LIN CH, RATLIFF B, RABADI M, MAIZEL J, TANOKUCHI R, ZHANG F, CAO J, GOLIGORSKY MS: Endothelial sirtuin 1 deficiency perpetrates nephrosclerosis through downregulation of matrix metalloproteinase-14: relevance to fibrosis of vascular senescence. $J$ Am Soc Nephrol 25: 276-291, 2014.

WANG P, DU B, YIN W, WANG X, ZHU W: Resveratrol attenuates $\mathrm{CoCl}_{2}$-induced cochlear hair cell damage through upregulation of Sirtuin1 and NF-אB deacetylation. PLoS One 8: e80854, 2013.

WANG RH, KIM HS, XIAO C, XU X, GAVRILOVA O, DENG CX: Hepatic Sirt1 deficiency in mice impairs mTorc2/Akt signaling and results in hyperglycemia, oxidative damage, and insulin resistance. $J$ Clin Invest 121: 4477-4490, 2011.

WEN D, HUANG X, ZHANG M, ZHANG L, CHEN J, GU Y, HAO CM: Resveratrol attenuates diabetic nephropathy via modulating angiogenesis. PLoS One 8: e82336, 2013.

YAMAKUCHI M: MicroRNA regulation of SIRT1. Front Physiol 3: Article 68, 2012.

YEUNG F, HOBERG JE, RAMSEY CS, KELLER MD, JONES DR, FRYE RA, MAYO MW: Modulation of NF-кBdependent transcription and cell survival by the SIRT1 deacetylase. EMBO J 23: 2369-2380, 2004. 